\title{
THE DIFFERENTIAL DIAGNOSIS BETWEEN PARINAUD'S CONJUNCTIVITIS AND CONJUNCTIVITIS NECROTICANS INFECTIOSA
}

BY

\author{
Prof. C. PaschefF \\ SOFIA
}

IN spite of numerous recent publications, more especially in German Ophthalmological literature, on the subject of Parinaud's conjunctivitis, the question of the nature of the disease remains obscure. Thus Bayer and Herrenschwand ${ }^{1}$ in two cases of an unusual type come to the conclusion that they were cases of Parinaud's conjunctivitis and, in spite of the fact that no histological examination was made, classed them as pseudo-tuberculosis. Others consider the disease to be a manifestation of tuberculosis ; Verhoeff ${ }^{8}$ proposes to call the disease leptothrix conjunctivae, and so on. In France and in Germany opinion is generally against the theory that the disease is due to tubercle. All this shows that there is a certain similarity in the symptoms of all these cases, but that there are different causes and also differences in the histological appearances which have unfortunately not always been investigafed. If in all these cases histological and bacteriological examinations had been made we should have had a more definite idea of the nature of the disease. The only undoubted similarity of all these published cases can be reduced to a few clinical symptoms which I propose to term "Parinaud's syndrome." These are the presence of a unilateral conjunctival inflammation accompanied by suppuration in the preauricular and submaxillary glands and a rise of temperature. Thus, just as in Mickulicz's disease, we have to deal not with a definite disease but with a syndrome of symptoms due to different causes.

In 1915 I separated from the chaos of so-called Parinaud's disease a type of conjunctivitis with definite symptomatology, evolution, pathological anatomy and aetiology which I called "Conjunctivitis Necroticans Infectiosa." In my researches on this disease I discovered one definite criterion that served to distinguish it from other cases of Parinaud's disease. This was the effect of inoculation on guinea pigs and rabbits which caused the death of these animals with characteristic white spots in the spleen.

As this criterion is the basis for differentiating the disease I have described from that described by Parinaud and his followers, I propose to give a brief comparative resumé of my results and those of Parinaud in the hope of creating a better base for future research work in this connection. 


\section{Symptomatology and Evolution}

Parinaud's conjunctivitis. (Three cases observed by Parinaud.)

\section{A.-General symptoms.}

1. Unilateral swelling of the parotid with reddening of the skin followed by either suppuration or resolution.

\section{Rise of temperature.}

\section{B.-Local ocular symptoms.}

The eyelids of the affected eye are swollen. Big granulations or red vegetations are found especially in the fornices and bulbar conjunctiva. They are translucent and pressed closely together (see Fig. 241 in Terson's "Ophtalmologie du Medicin Practicien," 1921). In places, especially over the sclera, yellow granulations, much smaller and closely pressed together are found. On the upper lid the vegetations show on their surface small polished areas but no regular ulceration. The secretion is mucous with some fibrinous deposit in the lower fornix. One of the vegetations reaches on to the lid margin. In another of Parinaud's cases the vegetations were of similar character but even more extensive.
Conjunctivitis necroticans infectiosa. (Three cases observed by me and one by Dr. Gunther.)

A.-General symptoms.

1. Unilateral swelling of the preauricular, parotid and submaxillary on the affected side, followed by suppuration in three cases and resolution in one.

2. Rise of temperature.

B.-Local ocular symptoms.

The eyelids of the affected eye are red and swollen. In the inferior conjunctival fornix there are numerous small white spots, the size of a millet seed, not sharply defined but merging into the surrounding red conjunctiva. Some are slightly elevated others excavated and ulcerated like phlyctenules. On the surface of the elevated spots there is a fine vascular network. These points and spots are to be found in the upper fornix without any vegetations (Fig. 1). They do not resemble ordinary follicles or trachoma granules, but, as Gunther remarks about his case, give rather the impression of superficial necrotic foci such as I have previously described. Another characteristic of these spots is that, after ulceration, they clean and cicatrize while similar fresh spots appear in other parts of the conjunctiva. In only one case I observed in the lower fornix a deep round yellow focus forming a small abscess (Fig. 4). 

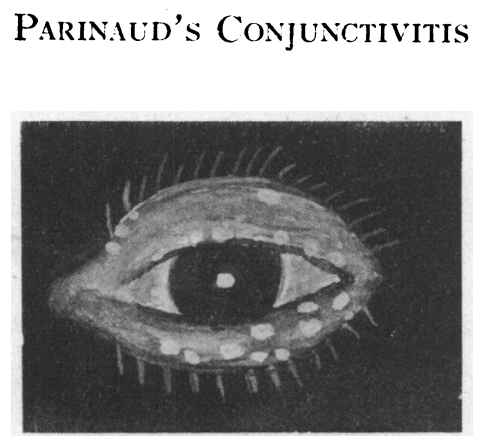

Fig. 1.

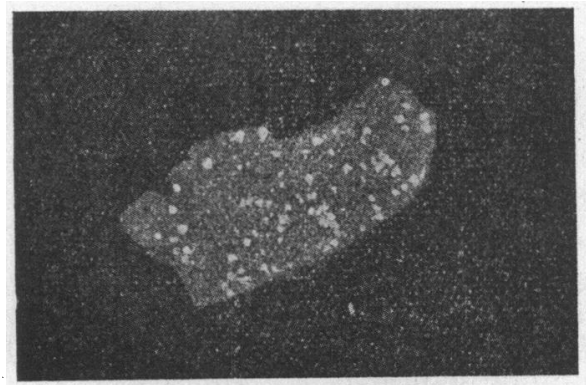

Fig. 2.

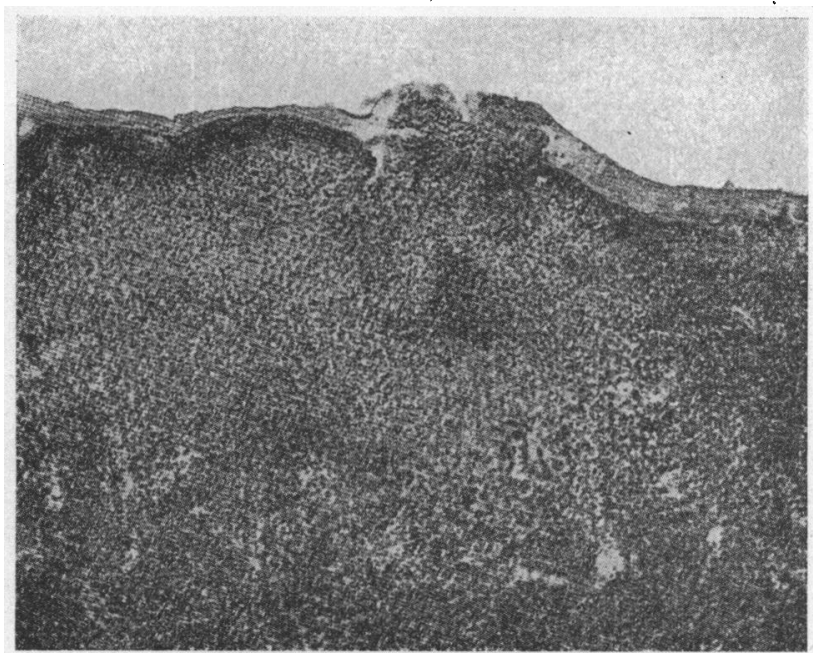

Fig. 3. 


\section{Evolution.}

In Parinaud's first case two months after continued cauterization with silver nitrate the granulations were still present. In a second case they disappeared in two months.

\section{II.-Pathological anatomy.}

Parinaud gives none. According to Morax the epithelium is normal without any breach of surface. The conjunctiva is thickened and infiltrated by lymphocytes with some macrophages similar to those described by Villard. There are no giant cells. In some cases distinct follicles surrounded by thickened conjunctiva are formed.

The necrosis described by Derby and Verhoeff differs from that found in my cases in the absence of polynuclear leucocytes and in the nature of the cause.

Reiss draws attention to the presence of plasma cells and considers that the necrosis described by the last two authors is accidental and has no connection with Parinaud's disease.

\section{Evolution.}

The inflammation is acute. The spots disappear in from two to three weeks. The glandular affection may last from two to three months. The evolution of the white spots passes through three stages:-

1. Period of necrosis during which their formation takes place.

2. Period of ulceration during which they ulcerate and become clean (Fig. 3).

3. Period of repair and cicatrization.

\section{II.-Pathological anatomy.}

The white spots in the conjunctiva are the result of a dense infiltration in the sub-conjunctival tissue. This forms a focus of exudation which consists of-

1. Polynuclear leucocytes.

2. Tissue cells in active proliferation.

3. A peripheral zone of lymphocytes.

In the foei necrosis rapidly develops. If the infiltration is superficial it ulcèrates and cicatrizes quickly, if deep it may develop into an abscess (Fig. 4).

The presence of many poly: nuclear leucocytes indicates the suppurating tendency of the disease with the rapidly formed central necrosis. 
III.-Experimental inoculations.

Parinaud $^{5}$, Morax ${ }^{4}$, Chaillous ${ }^{2}$ and Gourfein ${ }^{3}$ failed to get any positive results. The last author made numerous experiments on rabbits and guinea-pigs with material from a case in which granulations were present and came to the remarkable conclusion that Parinaud's disease cannot be transferred to animals. His case was cured in fifteen days but the adenopathy lasted six months without any suppuration.
III.-Experimental inoculations.

In all my cases, and also in that of Dr. Gunther, I succeeded in inoculating guinea-pigs subcutaneously and rabbits in the anterior chamber with excised portions of the affected conjunctiva. The guinea-pigs died in seven to eight days, the rabbits a little later. In both animals I always found in the spleen numerous small white necrotic points rich in polynuclear leucocytes and showing very early coagulation necrosis. I was thus able to reproduce the conjunctival white spots in the spleen of these animals and so establish a base for further research (Fig. 2).

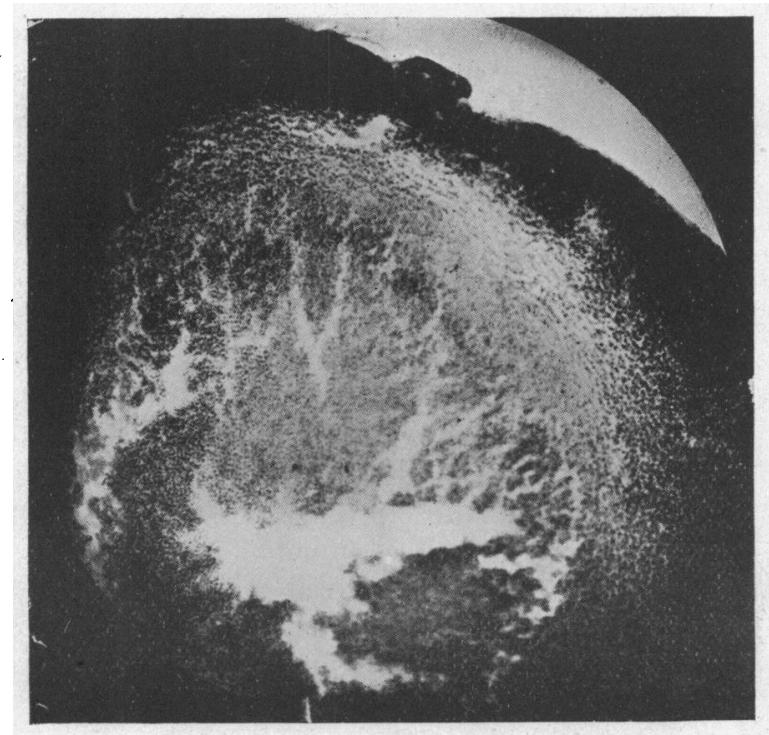

Fig. 4. 


$$
\text { IV.-Aetiology. }
$$

Bacteriological results of Parinaud, Gourfein, Chaillous and Morax were all negative.

Since with these data in hand I was able to define a new kind of conjunctivitis with the syndrome of Parinaud. The opinion that Parinaud's conjunctivitis is not a definite disease but only a

I succeeded in isolating in all the cases an organism to which I gave the name of "Micrococco bacillus polymorphicus necroticans." The morphological and biological characteristics of this cocco-bacillus are as follows (these results have been confirmed in Prof. Axenfeld's laboratory):-

Size between 0.25 and $2 \mu$ in culture. Shape usually that of a small coccus but sometimes that of a bacillus. It possesses neither cilia nor capsule and is Gram negative. It is both aerobic and anaerobic and does not grow at ordinary room temperatures. It does not liquefy Loeffler's serum or gelatine and forms no crust. It causes turbidity in bouillon, coagulates milk and gives an acid reaction. It does not form spores. It grows on the surface of agar without any colour and forms no gas ; it is non-motile. Cultures must be renewed every seven to eight days.

Bordet and Gengou is positive with antigen 0.0\%. Agglutination with the patient's serum 1/2000. Experimentally, the disease could be produced in guinea-pigs exactly as with the affected conjunctiva and was fatal to them in the same time with the same post-mortem appearances in the spleen. 
syndrome of symptoms seems to be making its way in France.* Parinaud failed to describe fully a definite disease with its pathological anatomy and bacteriology and his followers have not been more fortunate but have only added to the obscurity. While some have described the clinical picture in very various terms, others have dealt with the histology and still others with the bacteriology. In order to know the true picture of the disease it is necessary that all these various observations should be correlated so that the clinical picture, pathological anatomy and bacteriology should all be defined. This has been done in the case of "conjunctivitis necroticans infectiosa" and I, therefore, propose to give it the first place under the heading of Parinaud's syndrome. The future will tell us what its relation to pseudo-tuberculosis may be.

The histological changes in my cases may be expressed in a few words as consisting in the formation of small abscesses with a suddenly formed coagulating infectious necrosis. Such appearances according to Schneider of Heidelberg have not previously been observed in man, nor has pseudo-tuberculosis. Pseudo-tuberculosis, as seen by me in the guinea-pig in Prof. Kossel's laboratory in Heidelberg is quite difierent from the appearances I produced: Bayer and Herrenschwand who consider that Parinaud's disease is a form of pseudo-tuberculosis give no histological evidence for their assertion as they have not examined the infected human conjunctiva. The pictures and results obtained by them in the guinea-pig are similar to mine that were published previous to their observations. After publishing his first case, Herrenschwand informed me that he had seen a case very similar to the one published by me and asked me to let him have all my publications on the subject. $\mathrm{He}$ subsequently changed his opinion as he observed in a second case (Bayer's) that follicles were present. These, however, do not show up in his picture (Fig. 6) and were not submitted to any histological examination. A histological examination might possibly have shown that his trachoma-like granulations were in reality small abscesses similar to that described in my third case (Fig. 3). Those interested in the subject would do well to compare Bayer and Herrenschwand's figure 6 with figure 241 in Terson's "Ophtalmologie du Medicin Practicien" in order to understand the views held as to Parinaud's disease in France and Austria.

It is, therefore, quite clear that "Conjunctivitis Necroticans Infectiosa" does not appear in the inflamed conjunctiva under the

\footnotetext{
*Beavieux in his work on Parinaud's conjunctivitis ${ }^{10}$, says, "Pascheff in his paper on ' conjunctivitis necroticans infectiosa' (Arch. d'Ophtal., Feb., 1921), considers this disease to be quite distinct from that described by Parinaud. All these different infections characterised by a general and glandular affection must be classed together under the title of 'Parinaud's syndrome,' but due to various causes. In spite of the fact that my bacteriological researches proved negative, I consider that my cases are to be closely compared with those published by the Bulgarian professor."
} 
form of vegetations but of abscesses with central necrosis which, when on the surface, appear as white spots and ulcers (Fig. 3) but, when situated more deeply, appear as yellow grains. Further we are able readily to infect guinea pigs with the matter derived from these abscesses and white spots. The infected animals die quickly in from seven to eight days with characteristic white spots in the spleen. The microbacillus necroticans infectiosa was isolated in Dr. Angueloff's laboratory from these abscesses and with it we were able to reproduce the disease. This supplies the necessary test for the disease which is the characteristic infection of the guinea-pig. In spite of the simple nature of the test other observers (Chaillous, Morax, Gourfein, Reiss and others) have failed to obtain positive results in cases considered to be Parinaud's disease. It is on this account that I consider, the experimental and histological evidence to be of much more value than any clinical appearance.

As in other granulomatous diseases tuberculosis, pseudo-tuberculosis, and actinomycosis, conjunctivitis necroticans infectiosa is a focal inflammation. It is an acute suppurative necrosing inflammation which rapidly kills inoculated guinea-pigs and rabbits forming in their spleens similar foci of exudation.

To confirm the diagnosis it is not sufficient to observe the white spots and yellow grains described above; histological and experimental investigation is also necessary. Others and I myself have found the white spots present in cases which gave no result on the guinea-pig. For inoculation purposes it is advisable to use the white spots mainly as these contain the more active organism.

In conclusion I consider that I am justified in classing these cases as a definite disease under the name of "Conjunctivitis Necroticans Infectiosa" and separating them from the general type of case known as Parinaud's disease.

\section{BIBLIOGRAPHY}

1. Bayer and Herrenschwand.-Arch.f. Ophthal., p. 342, 1919.

2. Chaillous.-Annal. d'Ocul., p. 1, 1907; Soc. franç. d'Ophtal., p. 266, 1905.

3. Gourfein.-Rev. méd. de la Suisse romande, Feb. 20, 1907.

4. Morax.-Encycl. franc. d'Ophtal,, Vol. V, p. 774.

5. Parinaud.-Soc. d'Ophtal. de Paris, 1889.

6. Pascheff.-Klin. Monatsbl. f. Augenheilk., 1916 and 1917; Arch.d'Ophtal., 1921.

7. Reiss.-Arch. f. Ophthal., Vol. LXIII, p. 96.

8. Verhoeff and Derby.-Klin. Monatsbl.f. Augenheilk., p. 705, 1905.

9. Schöltz.-Arch. f. Augenheilk., p. 705, 1905.

10. Beaurieux.-Gaz. hebd. de Sci. méd. de Bordeaux, March, 1921. 